\title{
Advancement in Research Techniques on Medical Imaging Processing for Breast Cancer Detection
}

\author{
Sushma S J*, S C Prasanna Kumar** \\ * Instrumentation Technology, Visvesvaraya Technological University, Belgavi, India \\ ** Department of Instrumentation Technology, RVCE Bangalore, India
}

\begin{tabular}{l} 
Article Info \\
\hline Article history: \\
Received Sep 14, 2015 \\
Revised Nov 30, 2015 \\
Accepted Dec 18, 2015 \\
\hline Keyword: \\
Breast Cancer Detection \\
Cancer Detection \\
Mammogram \\
Radiology
\end{tabular}

Article Info

Article history:

Received Sep 14, 2015

Revised Nov 30, 2015

Accepted Dec 18, 2015

\section{ord:}

Cancer Detection

Radiology

\begin{abstract}
With the advancement of medical image processing, the area of the healthcare sector has started receiving the benefits of the modern arena of diagnostic tools to identify the diseases effectively. Cancer is one of the dreaded diseases, where success factor of treatment offered by medical sector is still an unsolved problem. Hence, the success factor of the treatment lies in early stage of the disease or timely detection of the disease. This paper discusses about the advancement being made in the medical image processing towards an effective diagnosis of the breast cancer from the mammogram image in radiology. There has been enough research activity with various sorts of advances techniques being implemented in the past decade. The prime contribution of this manuscript is to showcase the advancement of the technology along with illustration of the effectiveness of the existing literatures with respect to research gap.
\end{abstract}

Copyright $\left({ }^{\circ} 2016\right.$ Institute of Advanced Engineering and Science. All rights reserved.

\section{Corresponding Author:}

Sushma S J

Research Scholar

Instrumentation Technology

Visvesvaraya Technological University, Belgavi, India

E-Mail: sushjgowda@gmail.com

\section{INTRODUCTION}

In the recent days the early detection of cancer is very much indispensable for improving the survival rates, as it is one of the most challenging and deliberated topics which are being discussed among the research scientists. Cancer refers to some molecular events which are nothing but multiplication of a set of cells in a particular area of our body where the uncontrollable growth of cells can form microcalcifications and lump this type of structural distortion of cells are mentioned to as malignant tumors [1]. In case of a cancer cell it is observed that the cell overgrowth cannot be disallowed by the control system as their functionality become disabled, it has been found that the cancerous cells grow and split in the presence of a signal which is normally responsible for preventing the growth of any malignant tumor or cells. The development of these cells generates new characteristics which includes the formation of new cell structure and produce new enzymes which allows cells to divide and grow. Abnormalities in the cells which cause the cancer mainly develop from the mutation which can occur in the protein-encoded genes that is responsible for controlling the abnormal growth of the cells. And the genes which are often work to repair the DNA damage, sometimes don't work properly and result the further abnormalities like it allows the abnormal cells to divide more rapidly as compared to the normal cells. This study gives a better overview of cancerous cells where it is also said that if these enhance growth of the tissues are found in their original location then they are considered as benign else if those cells are found to be invasive in that case they spread very quickly and undesirably then those tissues are considered as malignant tissues. 
Section 1.1 discusses about the background of the study followed by problem description in Section 1.2. Section 2 discusses about the existing research work followed by discussion of research gap in Section 3 . Conclusion is discussed in Section 4.

\subsection{Background}

The study [2] [3] says there can be more than 200 different types of cancer, and cancerous cells can be developed in any organs of a body, it is found that there are 60 different organs which can be affected by the severe attacks of cancer. Some of the vital states of Breast cancers are i) Ductal Carcinoma and ii) Invasive Ductal Carcinoma. Ductal Carcinoma is also referred to the non-invasive or pre-invasive breast cancer. The Invasive Ductal Carcinoma is a very common type of breast cancer which usually originates from the milk duct of the breasts and Invasive ductal carcinoma spread through the wall of the ducts and develops into the fatty tissues of the breast. Various other forms of invasive breast cancer are medullary carcinoma, adenosquamous carcinoma, papillary carcinoma, Colloid carcinoma, cystic carcinoma etc. This paper emphasizes on the detail discussion of the various techniques which were developed for an effective Breast Cancer Detection and the classification. This study aims to fill the gap, which are associated with the development of the previous proposed techniques.

\subsection{The Problem}

Medical image processing has played a significant role in digital imaging that is used for investigation of the mammograms. At present, there exist various diagnostic tools that is used in digital imaging of breast region for identification of any abnormalities of cancerous type. This section discusses about the various imaging techniques and tools which were utilized for the breast cancer detection, it is concluded in the study of [3] [4] that there are very poor evidences that support the statement that clinical breast examinations along with screening mammograms can minimize the mortality rates from the breast cancer. Some of the important breast cancer imaging techniques is discussed over here.

\subsubsection{Mammography}

Mammography is an X-ray technique that was introduced specifically to examine the breast lesions [5]. Diagnosis, evaluation and the determination of the detected images and the results are done based on the different absorption schemes of the X-rays which can be occur between different types of breast tissues such as fat , fibro glandular tissues, cysts , tumors and various micro and macro calcifications. It has been diagnosed and seen that the macro calcifications are not usually related to the cancer. Figure 1 shows the visuals of normal mammogram image.

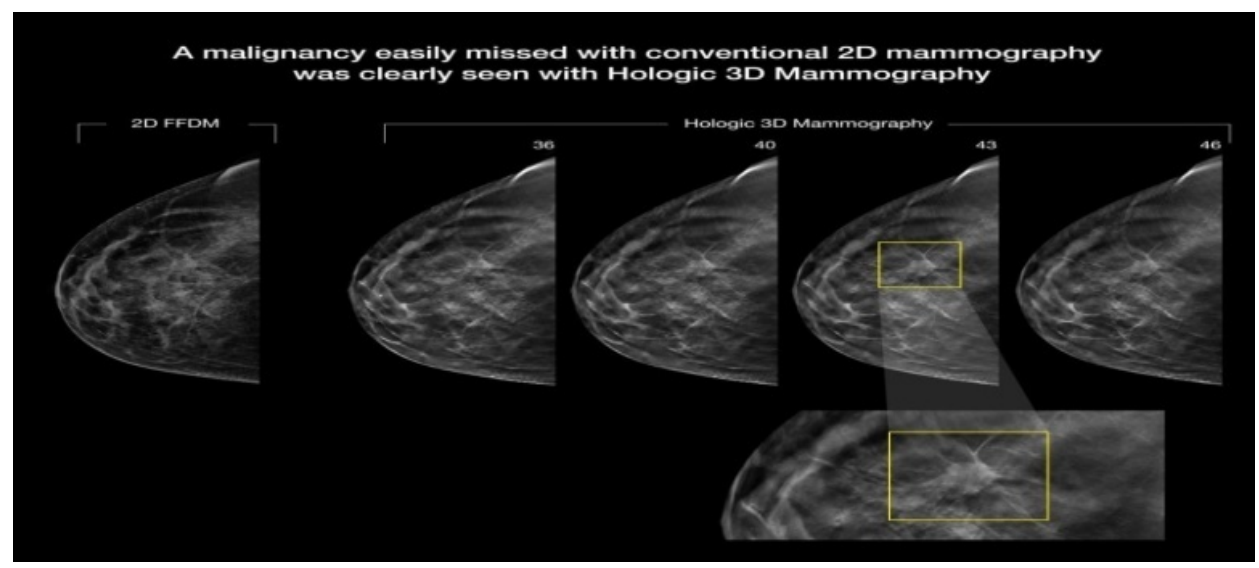

Figure 1. Example of Mammogram

\subsubsection{Computed Tomography (CT)}

There are so few benefits are associated with the Computed Tomography (Figure 2) as high cost efficiency is there to perform this technique in a human breast and high exposure of radiation is another demerit of this technique. It is not so much useful as indications of this technique result some limitations in the real time scenario [5]. 


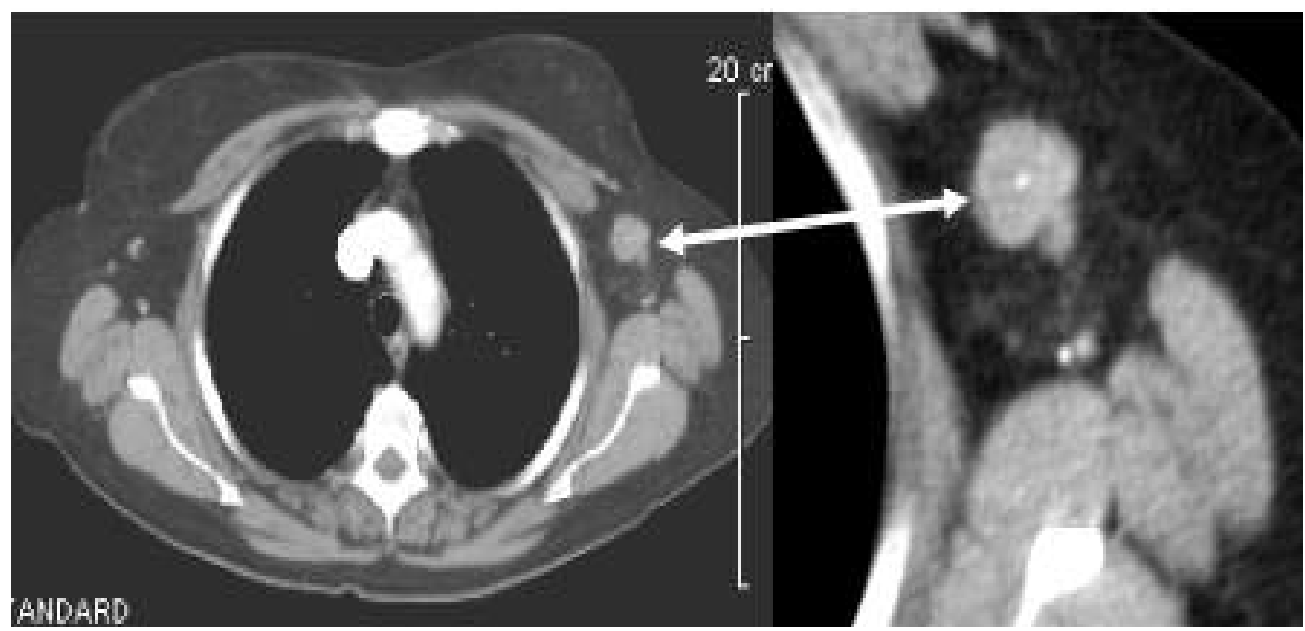

Figure 2. Example of CT scan image of breast

\subsubsection{Ultrasonography}

Ultrasound uses high frequency sound to investigate the internal structure of the tissues or nodes or masses inside the breast (Figure 3). It is one of the cost effective and frequently used imaging techniques for investigation of disease residing in breast. Normally used in visualizing pregnancy stages, ultrasound is also used in breast cancer. Ultrasound is one of the most efficient breast cancer imaging techniques which is applied to the mammography and the physical examination of the patient, Breast ultrasound is applied to discriminate a cyst and a solid mass, it is used to reveal the palpable irregularity which is not easy to detect in present of noisy measurements of the image. Ultrasound is not very much effective in detecting microcalcifications, but it is useful for the needle localization under some specific guidelines. Complicated imaging and their respective analysis cannot be performed on mammograms [5]. At present, we have both 3D and 4D ultrasound technologies to scan the oncological region [6].

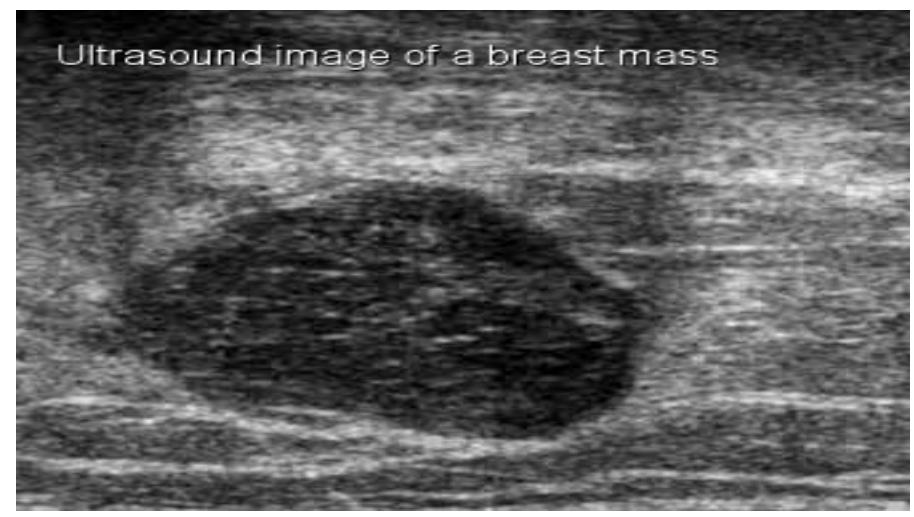

Figure 3. Example of Ultrasound

\subsubsection{Position Emission Tomographic Screening (PET)}

In this technique a radioactive chemical is administered to the patient before performing scan in order to see the hotspot areas under the scan. The hotspot areas are those areas of critical clinical significance. Early study of [5] suggested that metabolic activities raised in presence of cancer which is detectable using fluorine 18-labeled glucose. PET (Figure 4) is used to diagnose the benign from malignant lesions. It is also observed that PET may be a technique for the staging of breast cancers. 


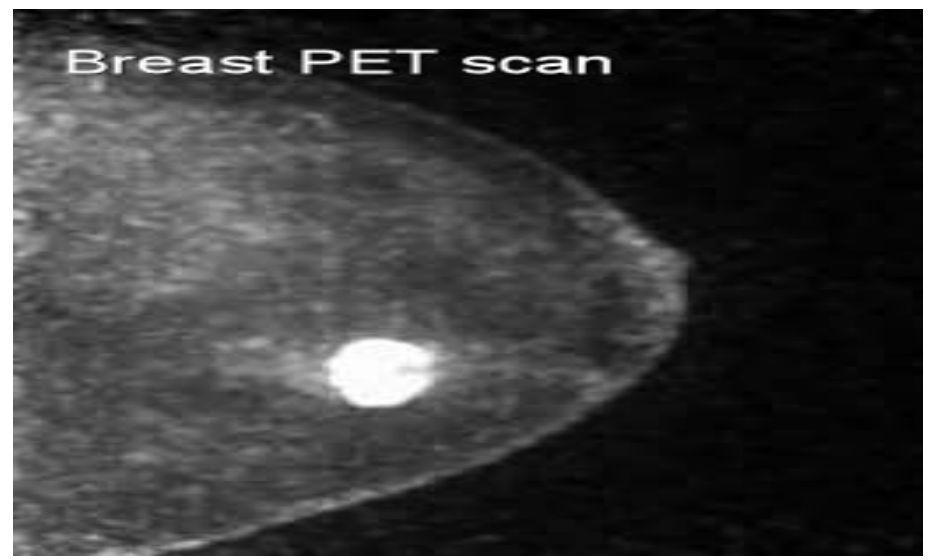

Figure 4. Example of PET Image

\subsubsection{Nuclear medicine Breast Imaging}

Concentrated Technetium-99 sestamibi has been detected in some breast cancers. The role of this technique is not well demarcated as it is not sufficient to differentiate lesions from malignant tumors (Figure 5). It is considered as a less efficient technique in the field of Cancer Detection techniques using image processing [7].
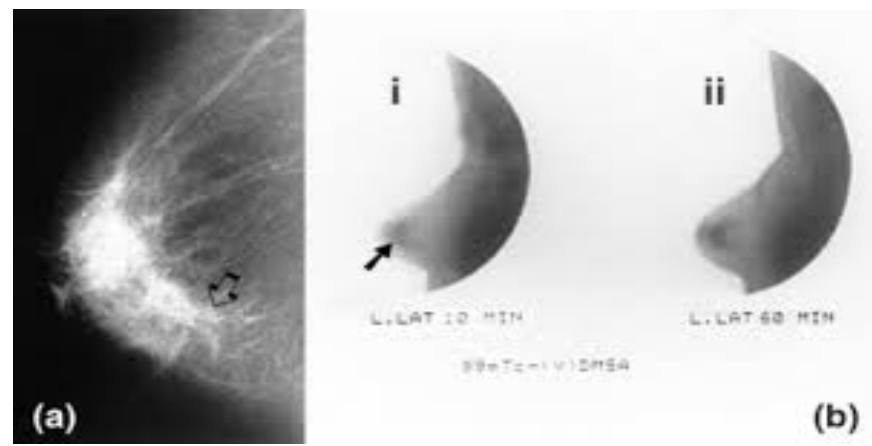

Figure 5. Example of Nuclear medicines

\subsubsection{Magnetic Resonance Imaging (MRI)}

The specificity of MRI technique is not so high, as it is applicable in various disease detections. As MRI does not give a better scan report of the micro calcifications but some few types of MRI such as Dynamic Contrast Enhancement MRI's can be useful to detect the malignancy of the non-palpable lesions (Figure 6). Breast cancer recurrence versus fibrosis presents the best indication for breast MRI [5].

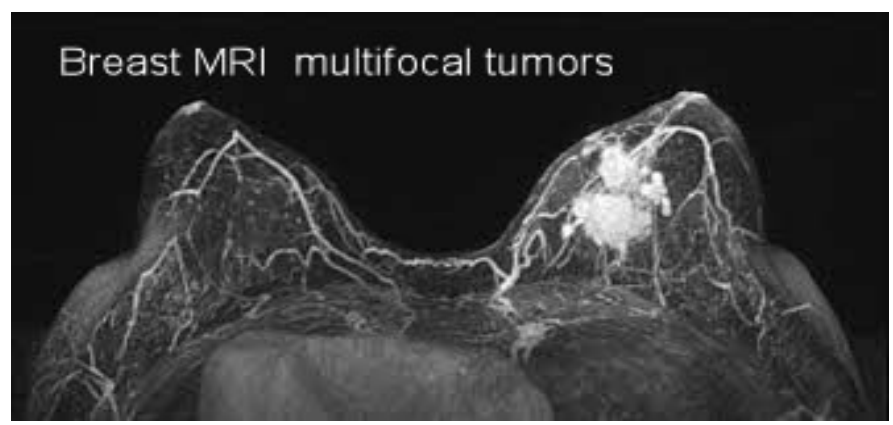

Figure 6. Example of MRI Imaging 


\subsubsection{Preprocessing of Mammograms}

From the information highlighted in the study of [7] it can be seen that current evidence supports that in the recent times the application of mammograms are much beneficial than in the past for the early breast cancer detection in women. Mammograms should be applicable for the women of all ages as long as she gets affected by any type of serious, chronic health disease. The current evidence gives a confirmation about the substantial benefits of mammograms for the women of 40's. Section IV will discuss about the work of past ten years where different types of techniques which have been developed to improve the contrast and the quality of the mammograms for the breast cancer detection have been discussed, which will be very much beneficial for the further stages of breast cancer detection pipeline. Cancer involves the abnormal growth or uncontrolled multiplication of cells in a particular region of any body. Breast Cancer is also a type of cancer refers to a form of malignant tumor, usually grown by the rapid division of breast cells. It is very much essential to apply the de-noising and Contrast enhancement techniques in the mammograms, as they do not provide a very good contrast between the normal glandular tissues and the malignant tumor tissues ,this happens because The X-ray attenuation between these two tissues represents very few dissimilarities. So the radiologists face problem when they manually differentiate the normal and cancerous tissues. This limitations associated with the breast cancer detection from the malignant tissues can be reduced by understanding the linear absorption coefficients of various tissues which discusses well about the better contrast of an image. Image Contrast which is acquired through the linear absorption coefficients is defined by the Beer-Lambart law.

$$
I=I_{0} e^{-\beta x}
$$

The above equation defines the intensity of the Electromagnetic (EM) wave $\left(\mathrm{I}_{0}\right)$ the attenuation coefficient of the material is defined as $\beta$ and the length of the material is $x$ through which the wave is being transmitted and here the (I) represents the electromagnetic wave. The noise is unwanted and redundant information present in an image and makes the detection of the cancerous malignant tissues more challenging. It has been seen that the noise present in an image increase with the pixel intensity where the local contrast and the image intensity are considered to be independent. This affects the mammograms, a solution for this problem has been proposed by various studies where the noise equalization technique has been applied to obtain the images where the local contrast is almost same all the image intensities. For the improvement of this technique various authors discussed the enhancement of the noise equalization technique. In this technique a point $\infty$ is considered as a neighborhood of an image location $(x, y)$. The local contrast of this neighborhood is calculated as

$$
C(x, y)=f(x, y)-\text { median }_{\infty}(x, y)
$$

Where $\mathrm{C}(\mathrm{x}, \mathrm{y})$ is the calculated as the local contrast, $\mathrm{f}(\mathrm{x}, \mathrm{y})$ is the image grey level at $(\mathrm{x}, \mathrm{y})$ and median $(\mathrm{x}, \mathrm{y})$ is the median grey level of the neighborhood $\infty$.

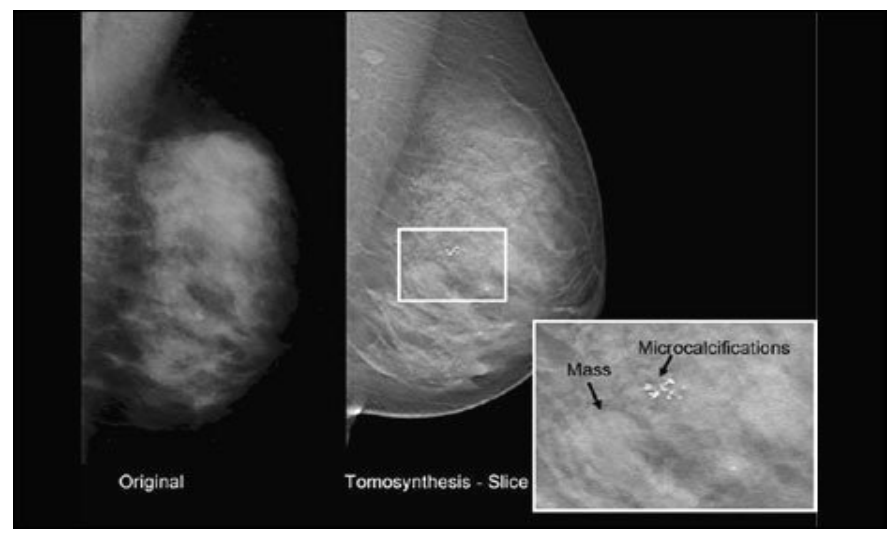

Figure 7. Identification of Microcalcification

Figure 7 shows the detection of the microcalcification, which is basically a portion identified to posses mineral deposit spread over specific portion of the mammogram. The specific identified position is

Advancement in Research Techniques on Medical Imaging Processing for Breast Cancer ... (Sushma S J) 
located by using bounding box. This is the normal way to identify the portion suspected of the cancer or certain form of abnormality in breast. The next section will discuss about the existing techniques in medical image processing towards breast cancer detection.

\section{EXISTING RESEARCH METHODOLOGIES}

There is a significant contribution of the medical image processing in the area of breast cancer detection. Majority of the existing system consists of preprocessing, feature extraction, segmentation, followed by detection of the cancerous portion. However, we will attempt differently to understand if there are any forms of optimization techniques being implemented in the past in order to enhance the probability of the detection rate. This section discusses about the techniques adopted by the researchers in order to detect the breast cancer from the mammogram. There are various studies in the past exploring an effective process of detection mechanism of breast cancer. Hence, in order to show better outcomes, we focus on only the significant studies carried out towards investigation of mammograms only from the most recent studies carried out in last 5 years. Table 1 will show the most significant work towards breast cancer detection.

Table 1. Survey of Existing Techniques

\begin{tabular}{|c|c|c|c|c|c|}
\hline & Approach & Author & Methodology & Outcome & Inference \\
\hline 1 & & Zheng et al. [8] & $\begin{array}{lcc}\text { Gabor } & \text { Filter, } & \text { Edge } \\
\text { Histogram } & \text { Descriptor }\end{array}$ & $90 \%$ accuracy & $\begin{array}{ll}\text { Not focused } & \text { on } \\
\text { classification, } & \text { no } \\
\text { benchmarking } & \end{array}$ \\
\hline 2 & Conventional & Nagi et al. [9] & Region of Interest & $\begin{array}{l}\text { Effective } \\
\text { segmentation }\end{array}$ & -Do- \\
\hline 3 & Techniques & Ganesan [10] & CAD based detection & $\begin{array}{l}\text { Good theoretical } \\
\text { discussion }\end{array}$ & $-\mathrm{N} / \mathrm{A}-$ \\
\hline 4 & & Hefnawy [11] & Watershed Segmentation & $\begin{array}{l}\text { Detection of } \\
\text { abnormal masses }\end{array}$ & $\begin{array}{l}\text { Not focused on } \\
\text { classification, no } \\
\text { benchmarking }\end{array}$ \\
\hline 5 & & $\begin{array}{l}\text { Masmoudi et al. } \\
{[12]}\end{array}$ & Local Binary Pattern & Does Classification & no benchmarking \\
\hline 6 & & Shareef [13] & Watershed Transformation & $90.47 \%$ accuracy & -Do- \\
\hline 7 & & Fleet et al. [14] & Haralick Feature & 88.9\% accuracy & -Do- \\
\hline 8 & & Sivakumar [15] & $\begin{array}{l}\text { Bilateral subtraction, ACO, } \\
\text { GA }\end{array}$ & $\begin{array}{lr}\text { Benchmarked study } \\
\text { with } & 91.9 \% \\
\text { accuracy } & \end{array}$ & $\begin{array}{l}\text { Not focused on } \\
\text { classification, }\end{array}$ \\
\hline 9 & $\begin{array}{l}\text { ACO-Based } \\
\text { Optimization }\end{array}$ & $\begin{array}{l}\text { Machraoui et al. } \\
{[16]}\end{array}$ & $\begin{array}{l}\text { ACO, Otsu method of } \\
\text { segmentation }\end{array}$ & $\begin{array}{l}\text { Lesser processing } \\
\text { time }\end{array}$ & -Do- \\
\hline 10 & & Bacha et al. [17] & $\begin{array}{l}\text { ROI, ACO, Markov Random } \\
\text { Field }\end{array}$ & $\begin{array}{l}\text { Effective } \\
\text { segmentation }\end{array}$ & $\begin{array}{l}\text { Not focused on } \\
\text { classification, no } \\
\text { benchmarking }\end{array}$ \\
\hline 11 & PSO-Based & Al-Faris [18] & $\begin{array}{l}\text { ROI, PSO, clustering, Level } \\
\text { Set Active Contour }\end{array}$ & $\begin{array}{l}\text { Improved } \\
\text { segmentation } \\
\text { performance }\end{array}$ & -Do- \\
\hline 12 & Optimization & $\begin{array}{l}\text { Mohemmed et al. } \\
\text { [19] }\end{array}$ & PSO, outlier detection & $\begin{array}{l}\text { Effective } \\
\text { segmentation }\end{array}$ & $\begin{array}{l}\text { Algorithm have time } \\
\text { complexity }\end{array}$ \\
\hline 13 & & Dheeba et al. [20] & $\begin{array}{l}\text { Wavelet neural Network, } \\
\text { CAD }\end{array}$ & $\begin{array}{l}\text { 93.67\& accuracy, } \\
\text { benchmarked study }\end{array}$ & $\begin{array}{l}\text { Not focused on } \\
\text { classification, }\end{array}$ \\
\hline 14 & & Zadeh et al. [21] & GA, Fuzzy Logic & 93\% accuracy & -Do- \\
\hline 15 & GA-based & Ahmad et al. [22] & GA-ANN & 97-98\% accuracy & -D0- \\
\hline 16 & Optimization & Yang et al. [23] & GA & $\begin{array}{l}\text { Better } \\
\text { interaction }\end{array}$ & -Do- \\
\hline 17 & & Keles et al. [24] & Neuro-fuzzy classification & 93\% accuracy & -Do- \\
\hline 18 & $\begin{array}{l}\text { Fuzzy Logic based } \\
\text { optimization }\end{array}$ & Singh et al. [25] & $\begin{array}{l}\text { Fuzzy C-means clustering, } \\
\text { k-means clustering }\end{array}$ & Good detection & $\begin{array}{l}\text { Not focused on } \\
\text { classification, no } \\
\text { benchmarking }\end{array}$ \\
\hline 19 & & Balanica et al. [26] & Fuzzy Logic & Prediction of disease & -Do- \\
\hline
\end{tabular}

\section{RESEARCH AND DISCUSSION}

This section highlights about the research gap of the breast cancer detection techniques using digital image processing till date. The following research gaps are found after reviewing some studies done in last ten years and the summery of the past ten years research works are presented in the Table-I which is included in the proposed survey study.

Table 1 briefly shows the existing techniques those are used for the early detection of breast cancers from mammograms. It has been seen in the maximum existing studies that the majority of the works 
discusses less about the practical applications of the proposed techniques rather than the mathematical and theoretical explanations. It has also been observed that majority of the work which are published till now have more emphasized in the detection of micro calcifications, Architectural distortions and masses, but the nature of the existing techniques are repetitive in nature. As the evidence says that the cancer detection using mammograms is one of the efficient techniques but the presence of better organization of studies and the performance parameters to represent the result analysis of the proposed techniques are pointedly missing in most of the recent studies. These narrowed review works do not give better outcomes which can be used for future pipeline of the research work as the monotonous types of techniques do not provide better solutions to compute a particular task.

Few benchmarked studies have been found in some of the papers as benchmarking makes a reader to understand that under which circumstances their experimental results or outcomes are better and useful for the future implementation and adoption of the work. It has been found that few papers described the repetitive nature of implementation of the proposed system and the result analysis does not give a better solution to reader to understand the concept.

\section{CONCLUSION}

The presented paper briefs about the advancement of the medical image processing towards the detection of breast cancer. The paper discusses that at present imaging technologies e.g. ultrasound, CT scan, PET scan, MRI etc are already in use. However, mammograms are still associated with various problems that either results in ineffective diagnostics or results in too many false positives, we have also seen that there are enough studies conducted towards detection of cancer in breast. Majority of the existing techniques are focused on enhancing the conventional techniques itself that reflects less novelty in this area. Hence the outcomes of such implementations doest yield much break through findings. In case of optimization techniques, there are existing various optimization techniques e.g. ACO, PSO, GA, Fuzzy logic etc. However, all these techniques are not found to focus on classification of the cancer stage. In fact the major findings of our investigation is that i) majority of the studies are not benchmarked, ii) negligence on focusing classification techniques of cancer stages or criticality, and iii) algorithm efficiency evaluations are almost none to be found in existing system. Hence, our future work will be to address such issues in real sense. We find that enhancement of the mammogram is one of the significant factor that was not focused by any researchers till date. A model for enhancing the contrast of mammogram for superior resolution will lead to better precision of detection of cancerous portion. Existing optimization techniques could be re-enhanced to suit the requirement of precise breast cancer detection.

\section{REFERENCES}

[1] H.U. Lemke, K. Inamura, C.C. Jaffe, R. Felix, Computer Assisted Radiology, Springer Science \& Business Media, 29-Jun-2013.

[2] Srivastava, Rajeev, Research Developments in Computer Vision and Image Processing: Methodologies and Applications, IGI Global, 30-Sep-2013

[3] U. Bick, F. Diekmann, Digital Mammography, Springer Science \& Business Media, 11-Mar-2010.

[4] G.R. Sinha, B.C. Patel, Medical Image Processing, PHI Learning Pvt. Ltd., 20-Jan-2014.

[5] D.M. Klieger, Saunders Essentials of Medical Assisting, Elsevier Health Sciences, 07-Aug-2013.

[6] T.M. Deserno, Biomedical Image Processing, Springer Science \& Business Media, 01-Mar-2011.

[7] C. Aktolun, W.N. Tauxe, Nuclear Oncology, Springer Science \& Business Media, 06-Dec-2012.

[8] Y. Zheng, "Breast cancer detection with Gabor features from digital mammograms", algorithms Vol.3, No. 1, pp. 44-62, 2010.

[9] J. Nagi, S.A. Kareem, F. Nagi, S.K. Ahmed, “Automated Breast Profile Segmentation for ROI Detection Using Digital Mammograms”, IEEE EMBS Conference on Biomedical Engineering \& Sciences (IECBES 2010), Kuala Lumpur, Malaysia, 30th November, 2010.

[10] K. Ganesan, U. Acharya, C.K. Chua, L.C. Min, K.T. Abraham, and K.H. Ng, "Computer-Aided Breast Cancer Detection Using Mammograms: A Review”, IEEE REVIEWS IN BIOMEDICAL ENGINEERING, VOL. 6, 2013

[11] A.A. Hefnawy, "An Improved Approach for Breast Cancer Detection in Mammogram based on Watershed Segmentation”, International Journal of Computer Applications (0975 Volume 75- No.15, August 2013.

[12] A.D. Masmoudi, N. G. B. Ayed, D. S. Masmoudi, and R. Abid, "LBPV descriptors-based automatic ACR/BIRADS classification approach", EURASIP Journal on Image and Video Processing, No. 1, pp. 1-9, 2013.

[13] S.R. Shareef, "Breast Cancer Detection Based on Watershed Transformation", IJCSI International Journal of Computer Science Issues, Vol. 11, Issue 1, No 1, January 2014.

[14] B.D.Fleet, J. Yan, D.B. Knoester, M. Yao, J.R. Deller and E.D. Goodman, "Breast Cancer Detection Using Haralick Features of Images Reconstructed from Ultra Wideband Microwave Scans", In Clinical Image-Based Procedures. Translational Research in Medical Imaging, Springer International Publishing, pp. 9-16, 2014. 
[15] R. Sivakumar, M. Karnan, "Intelligent optimization techniques for mammogram Image analysis through bilateral subtraction”, IEEE International Conference of Computational Intelligence and Computing Research, pp.1-4, 2010.

[16] A.N. Machraoui, M.A. Cherni, and M. Sayadi, "Ant Colony optimization algorithm for breast cancer cells classification", In Electrical Engineering and Software Applications (ICEESA), International Conference, pp. 1-6, 2013.

[17] A. Bacha, K. Kalti, N.E.B. Amara, and B. Solaiman, "Microcalcifications detection in mammograms based on Ant Colony Optimization and Markov Random Field", In Soft Computing and Pattern Recognition (SoCPaR), 6th International Conference of, pp. 191-196, 2014.

[18] A.Q.A. Faris, U.K. Ngah, N.A.M. Isa, and I.L. Shuaib, "Breast MRI tumour segmentation using modified automatic seeded region growing based on particle swarm optimization image clustering", In Soft Computing in Industrial Applications, Springer International Publishing, pp. 49-60, 2014.

[19] A.W. Mohemmed, M. Zhang, and W.N. Browne. "Particle swarm optimisation for outlier detection." In Proceedings of the 12th annual conference on Genetic and evolutionary computation, pp. 83-84. ACM, 2010.

[20] J. Dheeba, N.A. Singh, S.T. Selvi, "Computer-aided detection of breast cancer on mammograms: A swarm intelligence optimized wavelet neural network approach”, Journal of Biomedical Informatics, Vol. 49, pp. 45-52, 2014.

[21] H.G. Zadeh, O. Pakdelazar, J. Haddadnia, G.R. Rad, "Diagnosing Breast Cancer with the Aid of Fuzzy Logic Based on Data Mining of a Genetic Algorithm in Infrared Images”, Middle East Journal of Cancer vol.3, Iss.4, pp. 119-129, 2011.

[22] A.M. Ahmad, G. Muhammad, J.F. Miller, "Breast Cancer Detection Using Cartesian Genetic Programming evolved Artificial Neural Networks”, ACM-Proceedings of 14th Annula Conference on genetic and Evolutionary Computation, pp. 1031-1039, 2012.

[23] CH Yang, YD Lin, LY Chuang, and HW Chang, "Evaluation of Breast Cancer Susceptibility Using Improved Genetic Algorithms to Generate Genotype SNP Barcodes”, IEEE/ACM Transactions on Computational Biology and Bioinformatics, vol. 10, no. 2, 2013.

[24] A. Keles, A. Keles, "Extracting fuzzy rules for the diagnosis of breast cancer", Turkish Journal of Electrical Engineering \& Computer Sciences, vol.21, pp. 1495-1503, 2013.

[25] N. Singh, A.G Mohapatra, G. Kanungo, "Breast Cancer Mass Detection in Mammograms using K-means and Fuzzy C-means Clustering”, International Journal of Computer Applications (0975 - 8887) Volume 22- No. 2, May 2011.

[26] V. Balanica, I. Dumitrache, M. Caramihai, W. Rae, C. Herbst, "Evaluation of breast cancer risk by using Fuzzy logic”, U.P.B. Sci. Bull., Series C, Vol. 73, Iss. 1, 2011.

\section{BIOGRAPHIES OF AUTHORS}
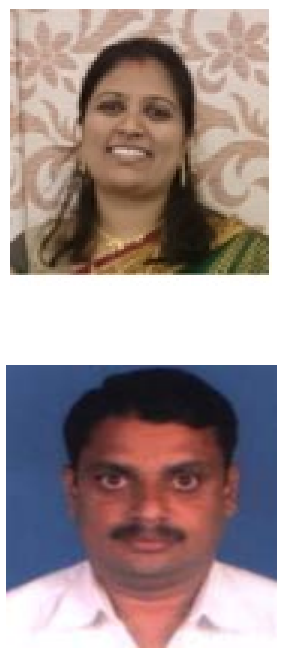

Sushma SJ is working as Associate Professor, Department of ECE, GSSS Institute of Engineering and Technology for women, Mysuru. She has got 14 years of teaching experience. She has obtained Bachelor of Engineering from Manglore University in the year 2001. In 2007 dshe obtained Master of Technology from Visveswaraya Technological University, Belagavi. Currently pursuing Ph.D. at Visveswaraya Technological University, Belagavi, India. She has published 2 papers national conferences Her area of interests include Image Processing, Computational Intelligence and Computer Networks.

Dr Prasanna Kumar S C is working as Professor and Head, Department of Instrumentation Technology, RV college of Engineering, Bangalore. He has got 18 years of teaching, 01 year of industry and 10 years of research experience. He did his Bachelor of Engineering and master of Engineering from Mysore University. He was awarded $\mathrm{PhD}$ in the year 2009 from Avinashlingham University, Tamilnadu. He has published over 14 papers in national and international conferences and around 24 papers in the international journals. He has received academic excellence award for the years 2008 and 2009. 